\title{
Phagocytic Functions and Tumor Necrosis Factor Secretion of Human Monocytes Exposed to Natural Porcine Surfactant (Curosurf)
}

\author{
CHRISTIAN P. SPEER, BETTINA GÖTZE, TORE CURSTEDT, AND BENGT ROBERTSON \\ Department of Pediatrics, University of Göttingen, Germany [C.P.S., B.G.]; Department of Clinical Chemistry, \\ Danderyd Hospital, Stockholm, Sweden [T.C.]; and Research Unit for Experimental Perinatal Pathology, \\ St. Göran's Hospital, Stockholm, Sweden [B.R.]
}

\begin{abstract}
In this study we have analyzed various phagocytic functions and tumor necrosis factor (TNF) secretion of human monocytes exposed to either a biochemically well-defined porcine surfactant or a purified phospholipid preparation. Adherence, random migration, and chemotactic response to zymosan activated serum and formyl-methionyl-leucyl-phenylalanine were normal in surfactanttreated monocytes; surfactant was not a chemotactic stimulus. In contrast, phagocytosis of Staphylococcus aureus by monocytes exposed to surfactant $(100 \mu \mathrm{g} / \mathrm{mL})$ or phospholipids $(100 \mu \mathrm{g} / \mathrm{mL})$ was slightly impaired [surfactant: at $30 \min \left(t_{30}\right) 48.5 \pm 11 \%, t_{60} 73.3 \pm 10.1 \%$; phospholipids: $\mathrm{t}_{30} 47.3 \pm 2.5 \%, \mathrm{t}_{60} 68.0 \pm 6.6 \%$; controls: $\mathrm{t}_{30} 66.6$ $\pm 9.9 \%, \mathrm{t}_{60} 81.0 \pm 6.6 \%, p<0.05$ at $\mathrm{t}_{30}$ for both, $p<0.05$ at $\mathrm{t}_{60}$ for phospholipids]. Due to the smaller number of $S$. aureus ingested, bactericidal activity of surfactant- or phospholipid-treated monocytes was slightly reduced when compared with controls. Surfactant or phospholipids had no bactericidal activity. Uptake of Candida albicans was identical in surfactant- or phospholipid-treated monocytes and untreated controls; the same was true for the number of Candida organisms ingested per cell. Phagocytosisassociated chemiluminescence and production of superoxide anion by monocytes of either source in response to phorbol myristate acetate and opsonized zymosan were also unaffected. Surfactant or phospholipids $(500 \mu \mathrm{g} / \mathrm{mL})$, however, effectively suppressed TNF secretion by resting and by lipopolysaccharide (LPS)-stimulated monocytes in a dose-dependent fashion, (LPS-stimulated monocyte controls: $3004 \pm 570 \mathrm{pg} / \mathrm{mL}$; LPS + surfactant: $426 \pm 162$ $\mathrm{pg} / \mathrm{mL} ;$ LPS + phospholipids: $28 \pm 9.6 \mathrm{pg} / \mathrm{mL} ; p<0.001$ for both). TNF is an important mediator of inflammation, and our data suggest that surfactant or phospholipids, by suppressing monocyte TNF secretion, may have an important role in down-regulating inflammatory reactions in the lung. (Pediatr Res 30: 69-74, 1991)
\end{abstract}

\section{Abbreviations}

CL, chemiluminescence

FMLP, formyl-methionyl-leucyl-phenylalanine

HBSS, Hanks' balanced salt solution

LPS, lipopolysaccharide

PMA, phorbol myristate acetate

TNF, tumor necrosis factor

Received August 9, 1990; accepted February 6, 1991.

Correspondence: Professor Christian P. Speer, M.D., Department of Pediatrics, University of Göttingen, Robert-Koch-Stranße 40, FRG-3400 Göttingen.

Supported by a grant from Deutsche Forschungsgemeinschaft (Sp 239/2-3) (C.P.S.).
Surfactant replacement therapy in severe neonatal respiratory distress syndrome effectively reduces respiratory distress syndrome-associated pulmonary morbidity and mortality in preterm infants. Immediately after intrabronchial administration of natural surfactant (human, bovine, porcine), there is a dramatic increase in oxygenation with a subsequent reduction in ventilatory requirements (1). However, there is only limited information about the effect of natural surfactant on human pulmonary monocytes and alveolar macrophages. These cells have an essential role in host defense $(2,3)$ as well as in the regulation of immune functions and inflammation (4-9). Available data on macrophage-surfactant interaction have been mostly derived from in vitro experiments using lung lavage materials from various species. However, most investigators have focused on a single aspect of macrophage function.

Our present study was initiated to examine the principal cell functions of monocytes-the macrophage precursors-in response to inflammation: adherence, random migration, chemotaxis, phagocytosis and killing of Staphylococcus aureus, uptake of Candida albicans, oxidative metabolism, and LPS-stimulated TNF-secretion. Each of these aspects was studied in monocytes either pretreated or directly exposed to a biochemically and physically well-defined porcine surfactant preparation (Curosurf) or a preparation of purified phospholipids; untreated monocytes were used as controls.

\section{MATERIALS AND METHODS}

Monocytes from healthy adult donors were isolated by FicollHypaque density gradient and purified by adherence and a $24-\mathrm{h}$ cultivation in Teflon culture bags at $37^{\circ} \mathrm{C}$ in $5 \% \mathrm{CO}_{2} / 95 \%$ air (10). The resulting cell preparation contained about $90 \%$ monocytes identified by nonspecific esterase stain (Technicon, Terry Town, New Jersey). More than $98 \%$ of the monocytes were viable as judged by a trypan blue exclusion test. For phagocytic assays, monocytes were resuspended in HBSS at a density of 5 $\times 10^{6}$ cells $/ \mathrm{mL}$ before use.

Preparation of surfactant. Curosurf was isolated from minced porcine lungs by a combination of washing, chloroform-methanol extraction, and liquid-gel chromatography. The isolated polar lipid fraction was dissolved in chloroform $(20 \mathrm{~mL} / \mathrm{g}$ of surfactant $)$ and sterilized by a high-pressure filter system (first filter $0.45 \mu \mathrm{m}$, second filter $0.20 \mu \mathrm{m}$ ). Subsequent steps of the procedure, including evaporation of the solvent and suspension of the surfactant in normal saline by gentle sonication $(50 \mathrm{~W}, 48 \mathrm{kHz})$ at a phospholipid concentration of $80 \mathrm{mg} / \mathrm{mL}$, were performed under sterile conditions with autoclaved glassware. Curosurf contains approximately $99 \%$ polar lipids, mainly phospholipids, and $1 \%$ hydrophobic, low molecular weight (surfactant protein-B, surfactant protein-C) proteins (11).

The phospholipids were isolated from Curosurf by liquid-gel 
chromatography on Sephadex LH-60 in chloroform/methanol $1: 1 \mathrm{vol} / \mathrm{vol}$ containing $5 \% 0.1 \mathrm{M} \mathrm{HCl}$ (12). The phospholipids, eluted between $60-120 \%$ of the column volume, were neutralized by addition of methanol/water to the fraction (final proportions between chloroform/methanol/water, 8:4:3 by volume) (13). After separation the unpolar phase was evaporated to dryness and analyzed for phospholipids (14) and proteins (12).

The purified phospholipids were suspended in $0.9 \% \mathrm{NaCl}$ by sonication and repeated freezing and thawing. The final concentration of phospholipids was $80 \mathrm{mg} / \mathrm{mL}$.

Preincubation of monocytes with surfactant. A total of $5 \times 10^{6}$ monocytes/mL HBSS were preincubated with various concentrations of surfactant, phospholipids, or $0.9 \%$ saline (controls) in a shaking water bath at $37^{\circ} \mathrm{C}$ for $30 \mathrm{~min}$. After preincubation the cells were washed twice with PBS and resuspended in HBSS at the optimal concentration; assays of monocyte functions were then immediately performed.

Adherence. Adherence to nylon fiber was determined by a modification of the method of MacGregor et al. (15). Forty mg of scrubbed nylon fiber (type 200; Fenwall Laboratories, Morton Grove, IL) were packed in $1-\mathrm{mL}$ plastic syringes. The length of the columns was adjusted to exactly $0.4 \mathrm{~mL}$. A total of $3 \times 10^{5}$ monocytes in $1 \mathrm{~mL}$ HBSS were preincubated with either surfactant, phospholipids, or saline and added in $0.5-\mathrm{mL}$ aliquots of prewarmed columns and allowed to filter at $37^{\circ} \mathrm{C}$ in $5 \% \mathrm{CO}_{2} /$ 95\% air. Monocytes in the effluent samples were counted (esterase stain) and the percentage of monocyte adherence calculated; each assay was performed in duplicate.

Chemotaxis. Random migration and chemotaxis of monocytes were evaluated by the leading front method using a modification of the Boyden Chamber Technique (48-well microchamber; Neuroprobe, Cabin John, MD) (16). Pooled serum activated by zymosan (Sigma, Munich, Germany; $15 \mathrm{mg} / \mathrm{mL}$ ) and FMLP $\left(5 \times 10^{-5} \mathrm{M}\right)$ was used as chemoattractant. In some experiments various concentrations of surfactant or phospholipids were added to the lower compartment; the pore size of the nitrocellulose filters was $8 \mu \mathrm{m}$ (Sartorius, Göttingen, Germany). Each assay was performed in triplicate.

Phagocytosis and bactericidal activity. A modification of the method of Quie and coworkers was used (10). Phagocytosis by monocytes was determined as the decrease in the number of viable extracellular bacteria ( $S$. aureus $502 \mathrm{~A}$ ) during incubation of bacteria and monocytes in the presence of serum. In addition, various concentrations of surfactant or phospholipids were directly added to the reaction mixture. The number of viable extracellular bacteria was determined by colony counting.

Intracellular killing of $S$. aureus was measured as the decrease in the number of viable intracellular bacteria ingested by monocytes (colony counting); assays were performed in duplicate.

Phagocytosis of Candida albicans. A histochemical assay was used to determine phagocytosis of $C$. albicans. Heat-killed $C$. albicans (approximately $2 \times 10^{7} / \mathrm{mL}$ ) in pooled serum were added to $1 \times 10^{7}$ monocytes $/ \mathrm{mL}$ and incubated in a shaking water bath at $37^{\circ} \mathrm{C}$ for $15 \mathrm{~min}$. In representative experiments, surfactant or phospholipids were directly added to the reaction mixture. Cells were stained with trypan blue to discriminate between engulfed and cell-associated nonengulfed yeast particles. The percentage of 200 monocytes that ingested one or more Candida organisms (phagocytic index) and the number of Candida organisms/200 monocytes were determined.

$C L$. Luminol-dependent $C L$ was measured using a luminometer (Biolumat LB 9505; Berthold, Wildbad, Germany); each assay was performed in triplicate. The reaction mixture, which was kept at $37^{\circ} \mathrm{C}$, consisted of $0.25 \times 10^{6}$ monocytes $/ \mathrm{mL}$ HBSS, and luminol (Sigma; final concentration $160 \mu \mathrm{mol}$ ), PMA (Sigma; $2.5 \mu \mathrm{g} / \mathrm{mL}$ ), or zymosan $(1 \mathrm{mg} / \mathrm{mL})$ previously opsonized with normal pooled serum was used as a stimulus.

Generation of $\mathrm{O}_{2}^{-}$. Release of $\mathrm{O}_{2}^{-}$by $1 \times 10^{5}$ monocytes $/ \mathrm{mL}$ was determined by superoxide dismutase (Sigma) inhibitable reduction of ferricytochrome c (Sigma) using PMA or opsonized zymosan (17)

TNF release by monocytes. A total of $2 \times 10^{4}$ monocytes in $200 \mu \mathrm{L}$ RPMI 1640 (Flow, Meckenheim, Germany) containing $10 \%$ FCS penicillin-streptomycin $(20 \mathrm{U} / \mathrm{mL})$, and L-glutamine $(100 \mu \mathrm{g} / \mathrm{mL})$ were plated to each well of a 96 -well microtiter plate (Flow). After $90 \mathrm{~min}$ incubation at $37^{\circ} \mathrm{C}$ in $5 \% \mathrm{CO}_{2} / 95 \%$ air, nonadherent cells were removed by gently aspirating the supernatant fluid and washing with HBSS three times.

New media $(200 \mu \mathrm{L})$ and LPS from Escherichia coli $026: \mathrm{B} 6$, (10-500 ng/well) and/or various concentrations of surfactant or phospholipids were added to some wells. After a 24-h cultivation at $37^{\circ} \mathrm{C}$ in $5 \% \mathrm{CO}_{2} / 95 \%$ air, supernatant was removed and immediately frozen at $-70^{\circ} \mathrm{C}$; TNF-concentrations were measured within $72 \mathrm{~h}$ by ELISA technique (T Cell Sciences, Inc., Cambridge, MA).

Statistical methods. Statistical analysis was performed by $t$ test for unpaired samples and Wilcoxon-Mann-Whitney test. Values are given as mean $\pm 1 \mathrm{SD}$.

\section{RESULTS}

The phospholipid compositions of surfactant (Curosurf) and the purified phospholipid fraction were similar, but the latter only contained trace amounts of proteins (Table 1).

Adherence. Adhesiveness of monocytes exposed to various concentrations of surfactant for $30 \mathrm{~min}$ was identical when compared with controls (Table 2 ). In additional experiments ( $n$ $=5)$, monocytes and surfactant $(1-100 \mu \mathrm{g})$ were directly added to the column; again, surfactant did not affect monocyte adherence (data not shown).

Random migration and chemotaxis. As demonstrated in Table 2 , during a 60 -min assay, random migration of monocytes pretreated with surfactant was similar to that of controls. In addition, the chemotactic response to zymosan-activated serum and to the synthetic chemotactic peptide FMLP was identical in monocytes exposed to surfactant and controls.

Surfactant $(1-100 \mu \mathrm{g})$ directly added to zymosan-activated serum and FMLP, did not affect the stimulated monocyte migration achieved with either stimulus (Table 2). Surfactant itself, when used as a chemotactic stimulus, had no chemotactic properties [controls, $56.7 \pm 12.4 \mu \mathrm{m} ; 100 \mu \mathrm{g}$ surfactant, $58.9 \pm 10.1$ $\mu \mathrm{m}(n=6)]$.

Phagocytosis and bactericidal capacity. Phagocytosis of $S$. aureus was identical in monocytes preincubated with surfactant $(100 \mu \mathrm{g} / \mathrm{mL})$ and in controls: $81 \pm 6.6 \%$ within 60 min and 83.2 $\pm 4.7 \%$ in controls $(n=4)$. Similarly, monocytes pretreated with surfactant killed $S$. aureus as efficiently as control monocytes. However, when surfactant $(100 \mu \mathrm{g})$ was directly added to the assay mixture, bacterial uptake was significantly reduced when compared with controls $\left(p<0.05\right.$ at $30 \mathrm{~min}\left(\mathrm{t}_{30}\right)$ ] (Fig. $\left.1 a\right)$. In addition, purified phospholipids $(100 \mu \mathrm{g})$ present in the assay mixture similarly reduced the phagocytic capacity of monocytes $\left(p<0.05\right.$ at $\left.t_{30}, t_{60}\right)$. The presence of surfactant or phospholipids

Table 1. Composition of Curosurf (mean $\pm S D$ for 22 batches used in clinical trials) and purified phospholipids

\begin{tabular}{|c|c|c|}
\hline Component & Curosurf & $\begin{array}{c}\text { Purified } \\
\text { phospholipids }\end{array}$ \\
\hline \multicolumn{3}{|l|}{ Phospholipids (mol \%) } \\
\hline Phosphatidylcholine* & $75.1 \pm 3.4$ & 75.3 \\
\hline Phosphatidylethanolamine & $8.5 \pm 2.0$ & 5.4 \\
\hline Phosphatidylserine & $1.0 \pm 0.7$ & 0.3 \\
\hline Phosphatidylinositol & $6.4 \pm 1.5$ & 8.4 \\
\hline Phosphatidylglycerol & $3.4 \pm 1.0$ & 2.4 \\
\hline Lysophosphatidylcholine & $0.7 \pm 0.4$ & 1.8 \\
\hline Sphingomyelin & $4.9 \pm 1.7$ & 6.5 \\
\hline Proteins (\% total phospholipids) & $1.0 \pm 0.3$ & $\leq 0.1$ \\
\hline
\end{tabular}

*Dipalmitoylphosphatidylcholine (\% total phosphatidylcholine) in Curosurf $46.4 \pm 1.7$, in purified phospholipids 42.4 . 
Table 2. Adherence, random migration, and chemotaxis of monocytes preincubated for 30 min with various concentrations of surfactant $(1-100 \mu \mathrm{g} / \mathrm{mL}$; controls: monocytes preincubated in HBSS)*

\begin{tabular}{|c|c|c|c|c|c|}
\hline \multirow[b]{2}{*}{ Parameters } & \multirow{2}{*}{$\begin{array}{c}\text { No. of } \\
\text { experiments } \\
(n)\end{array}$} & \multirow[b]{2}{*}{ Controls } & \multicolumn{3}{|c|}{ Surfactant $(\mu \mathrm{g} / \mathrm{mL})$} \\
\hline & & & 1 & 10 & 100 \\
\hline Adherence $(\%)$ & 5 & $99.2 \pm 0.7$ & $98.8 \pm 0.6$ & $98.3 \pm 1.7$ & $96.2 \pm 3.1$ \\
\hline Random migration $(\mu \mathrm{m} / \mathrm{h})$ & 6 & $46.7 \pm 7.1$ & $44.0 \pm 11.4$ & $56.1 \pm 4.4$ & $55.7 \pm 5.3$ \\
\hline \multicolumn{6}{|l|}{ Chemotaxis } \\
\hline $\mathrm{ZAS}(\mu \mathrm{m} / \mathrm{h})$ & 6 & $140 \pm 14.4$ & $132 \pm 23.4$ & $142 \pm 14.5$ & $145 \pm 12.1$ \\
\hline FMLP $(\mu \mathrm{m} / \mathrm{h})$ & 6 & $88 \pm 13.4$ & $86.1 \pm 10.7$ & $88.3 \pm 9.2$ & $87.3 \pm 8.1$ \\
\hline
\end{tabular}

* Values are mean $\pm 1 \mathrm{SD}$. ZAS, zymosan activated serum.
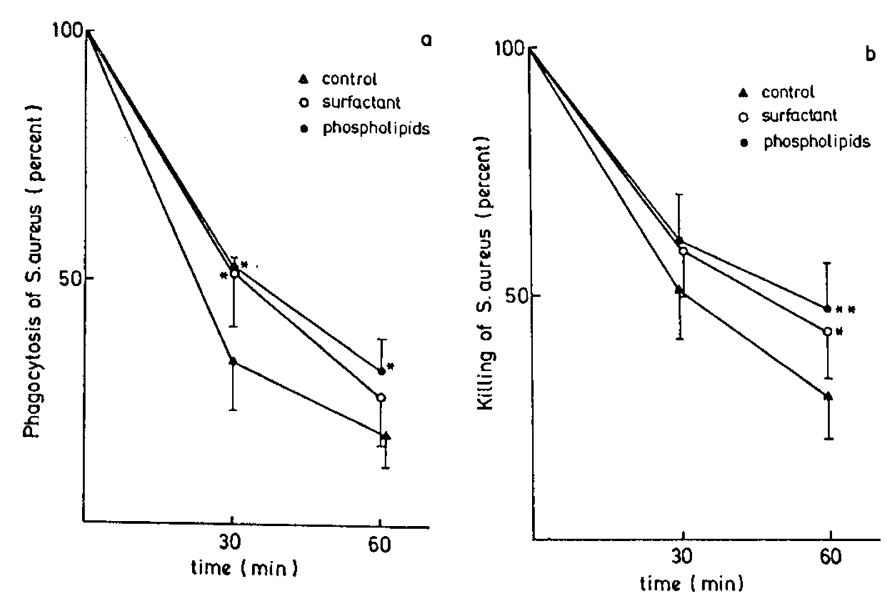

Fig. 1. Phagocytosis $(a)$ and killing $(b)$ of $S$. aureus by untreated monocytes (controls) and monocytes exposed to surfactant $(100 \mu \mathrm{g} / \mathrm{mL})$ or to phospholipids $(100 \mu \mathrm{g} / \mathrm{mL})$. Values represent mean $\pm 1 \mathrm{SD}$ for six experiments performed in duplicate. ${ }^{*}, p<0.05 ;{ }^{* *}, p<0.01$.

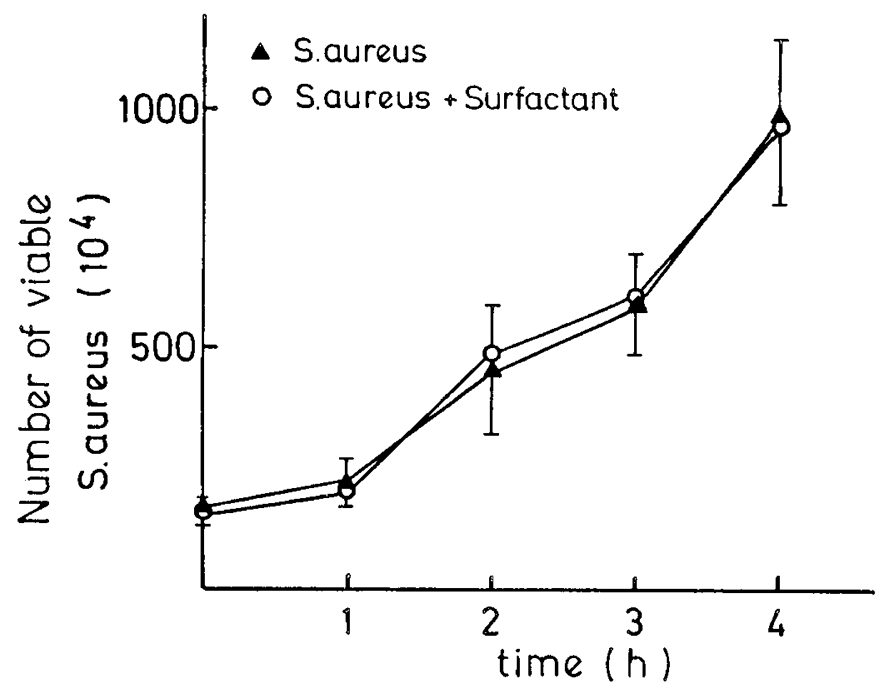

Fig. 2. Effect of surfactant on the growth curve of $S$. aureus during a 4-h assay $\left(37^{\circ} \mathrm{C}\right)$. Aliquots from the experimental and control tubes were removed at the given time interval and serially diluted in PBS to make agar pour plates for colony counting. Data represent mean \pm 1 SD of four experiments performed in duplicate.

in the killing assay effectively reduced the bactericidal activity of monocytes $\left(p<0.01\right.$ at $\left.t_{60}\right)$ (Fig. $\left.1 b\right)$. Interestingly, lower doses of surfactant or phospholipids $(1$ and $10 \mu \mathrm{g})$ did not affect bacterial uptake and killing.

Growth of $S$. aureus was not inhibited by surfactant $(100 \mu \mathrm{g})$ present during a 4-h assay (Fig. 2).

Phagocytosis of C. albicans. Preincubation of monocytes with surfactant $(100 \mu \mathrm{g}$ for $\mathrm{h})$ did not affect the capacity of the phagocytes to ingest $C$. albicans (data not shown). In addition, surfactant $(100 \mu \mathrm{g})$ directly added to the assay influenced neither phagocytic index nor $C$. albicans uptake per monocyte when compared with controls (Table 3 ).

Production of $\mathrm{O}_{2}^{-}$. Generation of $\mathrm{O}_{2}^{-}$by monocytes preincubated with surfactant $(100 \mu \mathrm{g}$ for $30 \mathrm{~min})$ was identical when compared with untreated controls $\left(5 \times 10^{6}\right.$ cells pretreated with surfactant $(\mathrm{nmol} / \mathrm{h})$ : resting cells, $0.9 \pm 0.4 ; \mathrm{PMA}, 9.2 \pm 0.7$; opsonized zymosan, $6.5 \pm 1.7$; controls $(\mathrm{nmol} / \mathrm{h})$ : resting cells, $1.2 \pm 0.4$, PMA, $8.9 \pm 0.7$, opsonized zymosan, $6.3 \pm 1.8(n=$ 5). Kinetic registration of PMA-stimulated $\mathrm{O}_{2}^{-}$production was $1.67 \pm 0.18 \mathrm{nmol} / \mathrm{min}$ in surfactant-pretreated monocytes and $1.53 \pm 0.13 \mathrm{nmol} / \mathrm{min}$ in controls. As summarized in Table 3, resting and stimulated production of $\mathrm{O}_{2}^{-}$by monocytes was not affected by surfactant present in the assay system.

Generation of $C L$. After stimulation with PMA, monocytes preincubated with surfactant $(100 \mu \mathrm{g}$ for $30 \mathrm{~min})$ as well as untreated monocytes generated identical amounts of CL. Additionally, CL by monocytes stimulated with opsonized zymosan was also similar in cells of either source (Table 4).

$T N F$ secretion of monocytes exposed to surfactant. As shown in Figure 3, unstimulated monocytes secreted only small amounts of TNF during a 24-h assay. However, monocytes exposed to surfactant $(500 \mu \mathrm{g} / \mathrm{mL})$ or phospholipids $(500 \mu \mathrm{g} /$ $\mathrm{mL}$ ) released even less TNF when compared with controls (surfactant, $p<0.05$; phospholipids, $p<0.01$ ).

Monocytes stimulated by LPS $(50 \mathrm{ng}-2.5 \mu \mathrm{g} / \mathrm{mL})$ secreted significant levels of TNF as compared to unstimulated monocytes (data not shown); the maximal release of TNF was induced by $2.5 \mu \mathrm{g} / \mathrm{mL}$ LPS. LPS-stimulated monocytes exposed to surfactant (final concentration $500 \mu \mathrm{g} / \mathrm{mL}$ ), however, secreted significantly less TNF activity $(p<0.001)$. LPS-stimulated monocytes cocultivated with phospholipids (final concentration 500 $\mu \mathrm{g} / \mathrm{mL}$ ) released even less TNF when compared with monocytes exposed to identical concentrations of surfactant $(p<0.001)$. As shown in Figure 4, surfactant or phospholipids inhibited TNF release by LPS-stimulated monocytes in a dose-dependent manner.

Viability of unstimulated and LPS-stimulated monocytes as well as monocytes exposed to surfactant or phospholipids was $>90 \%$ in all experiments as assessed by exclusion of trypan blue. Surfactant or phospholipids $(1-100 \mu \mathrm{g} / \mathrm{mL})$ that were added to the standards of the TNF-assay did not interfere with the assay system.

\section{DISCUSSION}

Monocytes - the precursors of pulmonary macrophages-play an essential role in cellular host defense as circulating phagocytes as well as immunoregulatory cells. In this study we evaluated the effect of a natural porcine surfactant preparation (Curosurf) on various functions of human monocytes. Curosurf contains about $99 \%$ phospholipids and about $1 \%$ low molecular weight apoproteins (SP-B, SP-C); its biochemical and physical properties are well defined (11). Structure and biophysical activity of the two hydrophobic apoproteins have been characterized (13).

Adherence is an important premigratory event in the initiation of the inflammatory response. Adhesiveness of monocytes that 
Table 3. Phagocytosis of $C$. albicans and generation of superoxide anion by monocytes directly exposed to surfactant $(100 \mu \mathrm{g} / \mathrm{mL}, n=5)$ and controls*

\begin{tabular}{|c|c|c|c|c|c|}
\hline & \multicolumn{2}{|c|}{ Phagocytosis of $C$. albicans } & \multicolumn{3}{|c|}{ Generation of $\mathrm{O}_{2}^{-}\left(\mathrm{nmol} / 10^{5}\right.$ monocytes $\left./ \mathrm{h}\right)$} \\
\hline & $\begin{array}{c}\text { Phagocytic } \\
\text { index }\end{array}$ & $\begin{array}{c}\text { No. of ingested } \\
\text { C. albicans } \\
\text { per cell }\end{array}$ & $\begin{array}{l}\text { Resting } \\
\text { value }\end{array}$ & PMA & $\begin{array}{c}\text { Opsonized } \\
\text { zymosan }\end{array}$ \\
\hline Without surfactant & $78 \pm 6.3$ & $2.6 \pm 0.2$ & $1.3 \pm 0.8$ & $9.7 \pm 0.8$ & $5.5 \pm 1.3$ \\
\hline With surfactant & $78 \pm 5.6$ & $2.6 \pm 0.2$ & $1.4 \pm 0.6$ & $9.7 \pm 1.1$ & $5.8 \pm 1.2$ \\
\hline
\end{tabular}

* Values are mean $\pm 1 \mathrm{SD}$.

Table 4. Generation of CL by monocytes preincubated with surfactant for $30 \mathrm{~min}[100 \mu \mathrm{g} / \mathrm{mL}(n=4)]$ and controls ${ }^{*}$

\begin{tabular}{|c|c|c|c|c|}
\hline & \multicolumn{4}{|c|}{ Stimulus } \\
\hline & \multicolumn{2}{|c|}{ PMA } & \multicolumn{2}{|c|}{ Opsonized zymosan } \\
\hline & Peak $(\mathrm{cpm})$ & $\mathrm{t}_{\max }(\min )$ & Peak $(\mathrm{cpm})$ & $\mathrm{t}_{\max }(\min )$ \\
\hline With surfactant & $6.67 \pm 2.6 \times 10^{7}$ & $1.92 \pm 0.4$ & $1.26 \times 10^{7} \pm 0.1 \times 10^{6}$ & $35.9 \pm 2.2$ \\
\hline Without surfactant & $5.75 \pm 3.5 \times 10^{7}$ & $1.72 \pm 0.3$ & $1.17 \times 10^{7} \pm 2.8 \times 10^{6}$ & $35.8 \pm 2.7$ \\
\hline
\end{tabular}

* Values are mean \pm 1 SD. $t_{\max }$, time interval between stimulation of cells and maximal generation of CL.

were preincubated with surfactant or directly exposed to Curosurf was normal when compared with untreated cells. In addition, random migration and chemotaxis in response to zymosanactivated serum and FMLP was identical to monocytes exposed to surfactant and controls. Surfactant, in the concentrations used, was not a chemotactic stimulus. Similar observations have been recently reported with rat alveolar macrophages; whole pulmonary surfactant and surfactant phospholipids did not affect macrophage chemotaxis. In contrast, a delipidated preparation of rat surfactant, consisting mainly of protein, augmented macrophage migration (18). The decreased migration of alveolar macrophages collected from monkeys exposed to ozone was nearly restored by addition of surfactant lining material (19), whereas pretreatment of rabbit alveolar macrophages with dipalmitoyl phosphatidylcholine caused decreased stimulated migration (20).

As demonstrated in our study, phagocytosis and killing of $S$. aureus 502 A were slightly impaired with monocytes that were directly exposed to Curosurf or to a purified phospholipid fraction. Previous studies on the effect of lung lavage surfactant on phagocytic functions of human alveolar macrophages have yielded conflicting results; in one study uptake of $S$. aureus by macrophages was increased in the presence of surfactant isolated from lung lavage fluid (4). Enhanced phagocytosis and killing of staphylococci were also observed with rat alveolar macrophages exposed to rat surfactant or human alveolar lining material (21, 22). The same phenomenon was observed in a rabbit model (23). Another study demonstrated that phagocytosis and killing of Streptococcus pneumoniae, Hemophilus influenzae, and $S$. aureus by macrophages were not affected by alveolar lining material (5). In contrast, data from in vivo animal experiments on newborn rabbits indicate that administration of homologous surfactant and some artificial phospholipid vesicle preparations reduces the phagocytic killing of group B streptococci by alveolar macrophages (24). These contradictory results can be explained, at least in part, by differences in the composition of surfactants used and by interspecies variations in macrophage activity. In fact, high concentrations of proteins in the surfactant material, especially Ig, may enhance bacterial uptake by improving opsonization of various pathogens.

Our own data suggest that lipid components of Curosurf rather than the small amounts of low molecular weight apoproteins could be responsible for impaired phagocytosis of staphylococci by interacting with membrane receptors of monocytes. A recent report has shown that the incubation of rat peritoneal and alveolar macrophages with alveolar lining material or purified lysophospholipids decreased the number of detectable $\mathrm{Fc}$ and complement receptors (25). Possible mechanisms could be un- specific binding of phospholipids to the macrophage membrane, i.e. covering of receptors that are involved in bacterial incorporation, or a modulation of surface receptor density by phospholipids. There is evidence that exogeneous lipids, phospholipids, lipoproteins, and fatty acids can be incorporated in the macrophage membrane $(26,27)$ and that these substances can either suppress (28) or enhance cellular functions of phagocytes.

As shown in our experiments, the uptake of $C$. albicans by macrophages exposed to Curosurf was identical in surfactanttreated and untreated cells; the same was true for the number of Candida organisms ingested per cell. With high doses of Curosurf $(1-2.5 \mathrm{mg} / \mathrm{mL})$ used by other investigators, the ingestion of Candida particles by monocytes was enhanced $(6,7)$. Because uptake of Candida is mainly mediated by mannose receptors on the monocyte membrane, surfactant could exert a different effect on these structures; this may explain the disparity between bacterial and fungal uptake by phagocytic cells in the presence of surfactant.

During phagocytosis of opsonized zymosan or perturbation of the cell membrane with PMA, monocytes exposed to Curosurf generated identical amounts of $\mathrm{CL}$ as untreated monocytes. It has been shown that the amount of $\mathrm{CL}$ produced depends on the extent of ingested particles (29). We did not observe an increased generation of CL in monocytes preincubated with Curosurf, although this has previously been described in rat alveolar macrophages pretreated with several unsaturated lipids (30). In a recent study, a suppressive effect of rabbit lung surfactant on CL generated by rabbit alveolar macrophages was demonstrated; again, lipid components were thought to be responsible for this alteration of cell function (31).

As shown in our experiment, production of $\mathrm{O}_{2}{ }^{-}$in response to PMA or opsonized zymosan was identical in surfactant-treated monocytes and untreated cells. Additionally, with high doses of surfactant $(1-2.5 \mathrm{mg} / \mathrm{mL})$, an increase in the nitroblue tetrazolium reduction of monocytes challenged by $E$. coli has been observed $(6,7)$. These data clearly demonstrate that, even in the presence of surfactant, monocytes have an intact oxidative metabolism. Conflicting results may be explained by differences in the assay procedures and the assay design and functional differences of alveolar macrophages from different species (32). Most importantly, there may be quantitative and qualitative differences in the phospholipids present in different species and surfactant materials. The role of surfactant phospholipids in the regulation of immune reactions in the lung has not been extensively studied. A previous investigation demonstrated that phosphatidylcholine and phosphatidylglycerol suppressed the stimulation of peripheral blood lymphocytes by concanavalin $\mathrm{A}$ 

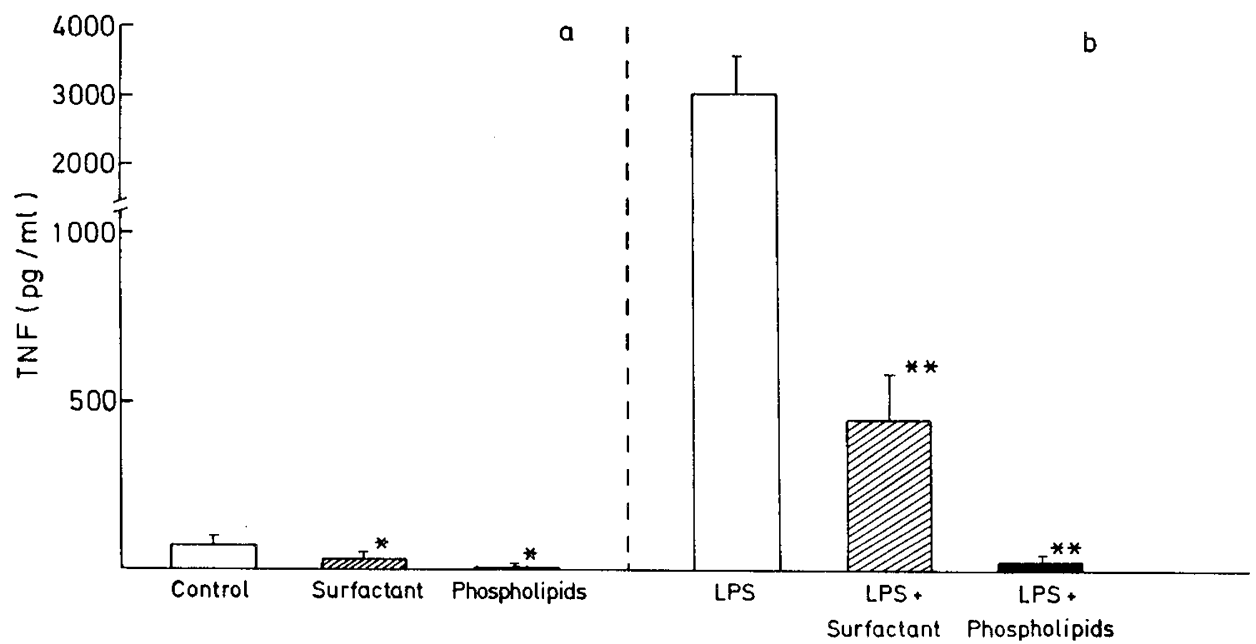

Fig. 3. TNF secretion by resting $(a)$ and LPS-stimulated monocytes $(b)(2.5 \mu \mathrm{g} / \mathrm{mL})$. Monocytes were exposed to surfactant $(500 \mu \mathrm{g} / \mathrm{mL})$ or phospholipids $(500 \mu \mathrm{g} / \mathrm{mL})$; untreated monocytes were used as controls. ${ }^{*}, p<0.05$, statistical significance of difference between untreated and surfactant- or phospholipid-treated monocytes. ${ }^{* *}, p<0.001$, statistical significance of difference between LPS-stimulated cells and cells that were exposed to either LPS and surfactant or LPS and phospholipids. Values represent mean \pm 1 SD for five experiments performed in triplicate.

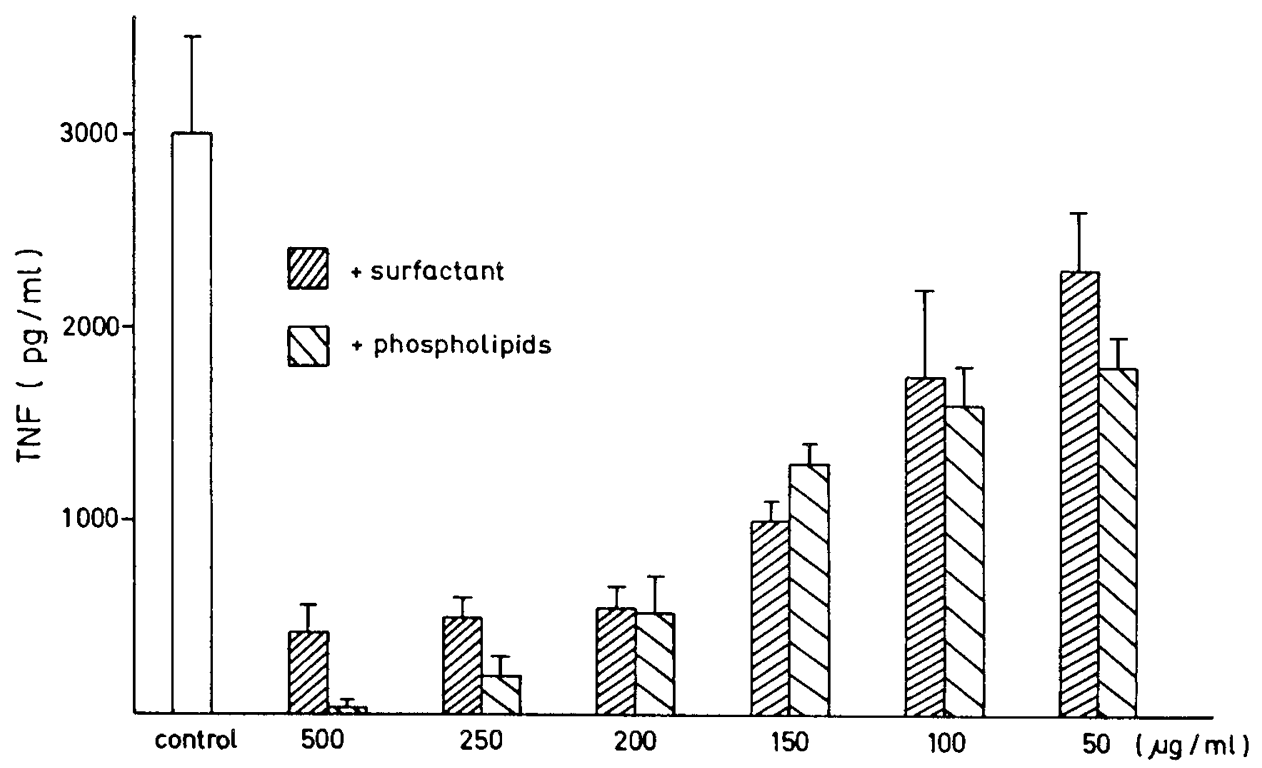

Fig. 4. Dose-dependent suppression of TNF release by LPS-stimulated monocytes exposed to various concentrations of surfactant or phospholipids (final concentration $500-50 \mu \mathrm{g} / \mathrm{mL}$ ).

pokeweed mitogen, or cocultivation with mitomycin-treated allogeneic lymphocytes (33). In addition, whole surfactant and purified surfactant lipids from human, pig, and rabbit lungs were shown to suppress in vitro proliferative responses to T cell and B cell mitogens as well as allogeneic mixed lymphocyte cultures; in all species the purified lipid fraction appeared to cause more suppression than did the whole surfactant (9). In contrast, phospholipids in surface active material were found to enhance cytotoxicity of human monocytes and alveolar macrophages; this enhancement of monocyte and macrophage cytotoxicity was only caused by some phospholipids, especially sphingomyelin, phosphatidylcholine, and phosphatidylglycerol, whereas phosphatidylinositol inhibited monocyte cytotoxicity (8). With our data, we provide evidence that porcine natural surfactant and purified phospholipids effectively suppress TNF secretion by resting and by LPS-stimulated monocytes in a dose-dependent fashion. TNF, a potent inflammatory mediator, appears to alter the hemostatic properties of the vascular endothelium by inducing the production of a procoagulant activity $(34,35)$. It also alters the pattern of antigenic expression (36-38) and cellular rearrangement of endothelial cells (39). TNF seems to be directly toxic to vascular endothelial cells (40), and pulmonary edema may be attributed to the resulting endothelial lesions. It is quite likely that TNF, among other factors, triggers the synthesis of leukotrienes, prostaglandin E2, and platelet activating factor and that the infiltration of polymorphonuclear leukocytes in the lungs may result in part from elaboration of these secondary mediators (41). Additionally, TNF stimulates adhesion of polymorphonuclear cells to endothelial cell surfaces (42) and mediates production of reactive oxygen radicals by granulocytes. It is likely that TNF has an important pathogenic role in the inflammatory process of chronic lung disease after severe neonatal respiratory distress syndrome, i.e. bronchopulmonary dysplasia. Decreased TNF secretion by monocytes and alveolar macrophages exposed to Curosurf may well contribute to a suppression of pulmonary inflammatory reactions. There is evidence, however, that TNF has an essential role in the host defense against Listeria monocytogenes: antilisterial resistance may be decreased after the exposure of macrophages to surfactant (43).

In conclusion, we have shown that human monocytes exposed to natural porcine surfactant and purified phospholipids exhibit basically normal phagocyte functions; only phagocytosis and killing of $S$. aureus were slightly impaired. 
Secretion of TNF, however, was markedly depressed in monocytes exposed to surfactant or phospholipids. These data suggest that surfactant may have an important and beneficial role in down-regulating inflammatory reactions in the lung.

\section{REFERENCES}

1. Collaborative European Multicenter Study Group 1988 Surfactant replacement therapy for severe neonatal respiratory distress syndrome: an international randomized clinical trial. Pediatrics 82:683-691

2. Green GM, Kass EH 1963 The role of the alveolar macrophage in the clearance of bacteria from the lung. J Exp Med 1 19:167-178

3. Johnston Jr RB 1988 Current concepts: immunology monocytes and macrophages. N Engl J Med 12:747-752

4. O'Neill SJ, Lesperance E, Klass DJ 1984 Human lung lavage surfactant enhances staphylococcal phagocytosis by alveolar macrophages. Am Rev Respir Dis 130:1177-1179

5. Jonsson S, Musher DU, Goree A, Lawrence C 1986 Human alveolar lining material and antibacterial defenses. Am Rev Respir Dis 133:136-140

6. Jarstrand C, Berggren P, Curstedt T, Johannson A, Robertson B, Wiernick A 1984 Influence of lung surfactant phospholipids on neutrophilic granulocytes and blood monocytes. Prog Respir Res 18:44-50

7. Wiernik A, Curstedt T, Johansson A, Jarstrand C, Robertson B 1987 Morphology and function of blood monocytes after incubation with lung surfactant. Eur J Respir Dis 71:410-418

8. Baughman RP, Mangels DJ, Strohofer S, Corser BC 1987 Enhancement of macrophage and monocyte cytotoxicity by the surface active material of lung lining fluid. J Lab Clin Med 109:692-697

9. Wilsher ML, Hughes DA, Haslam P 1988 Immunoregulatory properties of pulmonary surfactant: effect of lung lining fluid on proliferation of human blood lymphocytes. Thorax 43:354-359

10. Speer ChP, Gahr M, Wieland M, Eber St 1988 Phagocytosis-associated functions in neonatal monocyte-derived macrophages. Pediatr Res 24:213-216

11. Robertson B, Curstedt T, Johannson J, Jörnvall H, Kobayashi T 1990 Structural and functional characterization of porcine surfactant isolated liquid-gel chromatography. Prog Respir Res 25:237-246

12. Curstedt T, Jörnvall H, Robertson B, Bergmann T, Berggren P 1987 Two hydrophobic low-molecular-mass protein fractions of pulmonary surfactant: characterization and biophysical activity. Eur J Biochem 168:255-262

13. Johannson J, Curstedt T, Robertson B, Jörnvall H 1988 Size and structure of the hydrophobic low molecular weight surfactant-associated polypeptide. Biochemistry 27:3544-3547

14. Bartlett GR 1959 Phosphorus assay in column chromatography. J Biol Chem 234:466-468

15. MacGregor RR, Spagnuolo PJ, Lentnek AL 1974 Inhibition of granulocyte adherence by ethanol, prednisone, and aspirin, measured with an assay system. N Engl J Med 291:642-646

16. Bektas S, Goetze B, Speer ChP 1990 Decreased adherence, chemotaxis and phagocytic activities of neutrophils from preterm neonates. Acta Paediatr Scand 79:1031-1038

17. Speer ChP, Ambruso DR, Grimsley J, Johnston Jr RB 1985 Oxidative metabolism in cord blood monocytes and monocyte-derived macrophages. Infect Immun 50:919-92:1

18. Hoffmann RM, Claypool WD, Katyal SL, Singh G, Rogers RM, Dauber JH 1987 Augmentation of rat alveolar macrophage migration by surfactant protein. Am Rev Respir Dis 135:1358-1362

19. Schwartz LW, Christman CA 1979 Alveolar macrophage migration. Influence of lung lining material and acute lung insult. Am Rev Respir Dis 120:429439

20. Zeligs BJ, Nerurkar LS, Bellanti JA 1984 Chemotactic and candicidal responses of rabbit alveolar macrophages during postnatal development and the modulating roles of surfactant in these responses. Infect Immun 44:379-385

21. O'Neill S, Lesperance E, Klass DJ 1984 Rat lung lavage surfactant enhances bacterial phagocytosis and intracellular killing by alveolar macrophages. Am Rev Respir Dis 130:225-230
22. Juers JA, Rogers RM, McCurdy JB, Cook WW 1976 Enhancement of bactericidal capacity of alveolar macrophages by human alveolar lining material. $\mathrm{J}$ Clin Invest 58:271-275

23. LaForce FM 1976 Effect of alveolar lining material on phagocytic and bactericidal activity of lung macrophages against Staphylococcus aureus. J Lab Clin Med 88:691-699

24. Sherman MP, D'Ambola JB, Aeberhard EE, Barrett CT 1988 Surfactant therapy of newborn rabbits impairs lung macrophage bactericidal activity. $\mathrm{J}$ Appl Physiol 65:137-145

25. Coonrod JD, Yoneda K 1983 Effect of rat alveolar lining material on macrophage receptors. J Immunol 130:2589-2596

26. Schroit AJ, Gallily R 1979 Macrophage fatty acid composition and phagocytosis: effect of unsaturation on cellular phagocytic activity. Immunology 36:199-205

27. Bates SR, Murphy L, Fesig Z, Kanatawa T, Jetz GS 1984 Very low density lipoproteins promote triglyceride accumulation in macrophages. Arteriosclerosis 4:103-104

28. Wiernik A, Jarstrand C, Julander I 1983 The effect of intralipid on mononuclear and polymorphonuclear phagocytes. Am J Clin Nutr 37:256-261

29. McPhail LC, DeChatelet LR, Johnston Jr RB 1979 Generation of chemiluminescence by a particular fraction isolated from human neutrophils. Analysis of molecular events. J Clin Invest 63:648-655

30. Webb DSA, Jesja EL 1986 Enhanced luminol-dependent chemiluminescence of stimulated rat alveolar macrophages by pretreatment with alveolar lining material. J Leukocyte Biol 40:55-64

31. Hayakawa H, Myrvik QN, St Clair RW 1989 Pulmonary surfactant inhibits priming of rabbit alveolar macrophage. Am Rev Respir Dis 140:1390-1397

32. Nguyen BT, Peterson PK, Verbrugh HA, Quie PG, Hoidal JR 1982 Differences in phagocytosis and killing by alveolar macrophages from humans, rabbits, rats, and hamsters. Infect Immun 36:504-509

33. Ansfield JU, Benson BJ 1979 Identification of the immunosuppression components of canine pulmonary surface active material. J Immunol 122:10621066

34. Nawroth PP, Stern DM 1986 Modulation of endothelial cell hemostatic properties by tumor necrosis factor. J Exp Med 163:740-745

35. Bevilacqua MP, Pober JS, Majeau GR, Fiers W, Cotran RS, Jimbrone Jr MA 1986 Recombinant tumor necrosis factor induces procoagulant activity in cultured vascular endothelium: characterization and comparison with the actions of interleukin 1. Proc Natl Acad Sci USA 83:4533-4537

36. Collins T, Lapierre LA, Fiers W, Strominger JL, Pober JS 1986 Recombinant human tumor necrosis factor increases nRNA levels and surface expression of HLA-A, B antigen in vascular endothelial cells and dermal fibroblasts in vitro. Proc Natl Acad Sci USA 83:446-450

37. Pober JS, Bevilacqua MP, Mendrick DL, Lapierre LA, Fiers W, Gimbrone $\mathrm{J}_{\mathrm{r}}$ MA 1986 Two distinct monokines, interleukin 1 and tumor necrosis factor, each independently induce biosynthesis and transient expression of same antigen on the surface of cultured human vascular endothelial cells. J Immunol 136:1680-1687

38. Pohlmann TH, Stanness KA, Beatty PG 1986 An endothelial cell surface factor(s) induced in vitro by lipopolysaccharide, interleukin 1 , and tumo necrosis factor- $\alpha$ increases neutrophil adherence by a CDw18-dependent mechanism. J Immunol 136:4548-4553

39. Stolpen AH, Guinan EC, Fiers W, Pober JS 1986 Recombinant tumor necrosis factor and immune interferon act singly and in combination to reorganize human vascular endothelial cell monolayers. Am J Pathol 123:16-24

40. Sato N, Goto T, Haranaka K 1986 Actions of tumor necrosis factor on cultured vascular endothelial cells: morphologic modulation, growth inhibition, and cytotoxicity. J Natl Cancer Inst (Bethesda) 76:1113-1121

41. Beutler B, Cerami A 1987 Cachectin: more than a tumor necrosis factor. $N$ Engl J Med 316:379-386

42. Gamble JR, Harlan JM, Klebanoff SJ, Vadas MA 1985 Stimulation of neutrophils to umbilical vein endothelium by human recombinant tumor necrosis factor. Proc Natl Acad Sci USA 82:8667-8771

43. Nakane A, Minagawa T, Kato K 1988 Endogenous tumor necrosis factor (cachectin) is essential to host resistance against listeria monocytogenes infection. Infect Immun 56:2563-2569 